\title{
0 ÚLTIMO REFÚGIO DO INDIVÍDUO: O IDEAL DE AUTONOMIA NA CRÍTICA DE ÁLVARO LINS
}

\section{Eduardo Cesar Maia}

RESUMO: Um dos valores fundamentais preconizados pelo crítico pernambucano Álvaro Lins, desde o princípio de sua carreira, foi o de colocar a autonomia individual como centro e fundamento da crítica literária. Ele seguia, portanto, na contracorrente das tendências de valorização, por um lado, da rigidez metodológica ou, por outro, da militância ideológica como norte da atividade crítica. $\mathrm{O}$ indivíduo seria, nessa perspectiva, o último refúgio contra todas as formas totalizantes e dogmáticas de compreensão da realidade.

PALAVRAS-CHAVE: Crítica literária; Álvaro Lins; Teoria da Literatura; Impressionismo crítico.

ABSTRACT: From the beginning of his career, one of the fundamental values defended by the Brazilian critic Álvaro Lins was that of individual autonomy, which he placed at the centre of his practice of literary criticism. He went, therefore, against the prevailing critical trends, which valued, instead, methodological rigor, on the one hand, and, on the other, ideological militancy as the guidelines for the activity of the critic. The individual would be, thus, in his perspective, the last shelter against all totalizing and dogmatic forms of understanding reality.

KEYWORDS: Literary Criticism; Álvaro Lins; Theory of Literature; Critical Impressionism. 


\section{O CRÍTICO E SUAS CIRCUNSTÂNCIAS}

Álvaro Lins (1912-1970) nasceu em Pernambuco, na cidade de Caruaru. Intelectual incansável e versátil, exerceu, muitas vezes paralelamente, as atividades de jornalista, crítico cultural, historiador, professor, escritor e diplomata. Sua formação superior se deu na Faculdade de Direito do Recife; já a formação propriamente literária foi a de um autodidata, o que era bastante comum até então. ${ }^{1}$

No que se relaciona mais especificamente à sua atividade como crítico literário profissional, uma data fundamental é o ano de 1940, mais precisamente o dia 10 de agosto, quando inicia a colaboração, que duraria mais de uma década, de forma intermitente, como crítico titular do importante jornal carioca Correio da Manhã. Nesse período, foi, sem dúvida, um dos críticos mais influentes do país. O poeta Carlos Drummond de Andrade, em reconhecimento ao grande poder retórico e à capacidade argumentativa do crítico pernambucano, afirmou, em artigo no Jornal do Brasil, que ele

Foi o imperador da crítica brasileira, entre 1940 e 1950. Cada rodapé de Álvaro, no Correio da Manhã, tinha o dom de firmar um valor literário desconhecido ou contestado. E quando arrasava um autor, o melhor que o arrasado tinha a fazer era calar a boca. ${ }^{2}$

De fato, uma opinião do crítico emitida num de seus rodapés hebdomadários - nos quais acompanhava rigorosamente a literatura feita na época - muitas vezes determinava o sucesso ou o fracasso de uma obra ou mesmo da carreira de um aspirante a escritor. Os nomes consagrados da literatura brasileira também não escapavam de suas rigorosas avaliações, o que, muitas vezes, gerava polêmicas e acrescentava dinamismo à vida cultural da época. Essa vontade de participação e de influência nos debates literários é uma das marcas da crítica de Álvaro Lins. Para ele,

1 Para um perfil crítico-biográfico de Álvaro Lins, com boa contextualização histórica, ver: BOLLE, Adélia Bezerra de Meneses. A obra de Álvaro Lins e sua função histórica. Rio de Janeiro: Vozes, 1979. Remeto, ainda, à edição especial da Revista Continente, publicada no Recife pela Companhia Editora de Pernambuco, em novembro de 2012, na qual pode ser encontrada uma série de textos, de autores diversos, que se propõem a resgatar a trajetória de homem público do intelectual pernambucano, revisitar seu pensamento crítico e reavaliar sua contribuição às letras e à crítica literária brasileira.

2 A referência completa da entrevista é: ANDRADE, Carlos Drummond de. "O escritor e sua paixão". Jornal do Brasil, 6 jun. 1970. 
Um crítico não se define somente pelo valor estritamente literário e artístico de suas páginas, mas pela sua atuação na vida literária, pela sua influência, pelos resultados dos seus trabalhos, pelos erros que condena ou evita, pelas realizações que sugere ou provoca com as suas ideias. Um crítico é uma espécie de político no mundo das letras, um "regente" da literatura. ${ }^{3}$

Entre os anos de 1941 e 1963, ${ }^{4}$ Álvaro Lins coligiu, num total de sete volumes, cada um deles intitulado muito apropriadamente Jornal de crítica, a parte mais relevante de sua contribuição jornalística à crítica literária brasileira do período. Esses artigos e ensaios que, em conjunto, somam mais de 2 mil páginas, foram publicados originalmente na grande imprensa, principalmente no jornal carioca Correio da Manhã. Em sua maioria, tinham como finalidade precípua o recenseamento de novos autores e o comentário crítico de obras recém-publicadas, além da discussão de temas literários, políticos e ideológicos do momento. Ainda que seus artigos e ensaios fossem quase invariavelmente motivados por algum desses fatores circunstanciais, em alguns desses rodapés, no entanto, o crítico caruaruense refletiu não exclusivamente sobre obras concretas ou temas da ocasião, mas a respeito do ato crítico em si: o papel da literatura e da crítica literária, as perspectivas dos demais críticos e teóricos da época e também sobre aqueles pensadores do passado que influenciavam sua visão pessoal de crítica e de literatura.

Nesse sentido, pretende-se aqui oferecer, com a análise desses textos de caráter essencialmente jornalístico, uma visão alternativa ao lugar-comum estabelecido pela crítica universitária de que as análises literárias de Álvaro Lins padeciam fundamen-

\footnotetext{
3 LINs, Álvaro: “Um crítico do mundo moderno”. In: Jornal de crítica ( $3^{\text {a }}$ série). Rio de Janeiro: José Olympio, 1944, p. 50. As próximas referências das citações dos Jornais de crítica de Álvaro Lins se darão no corpo do texto, entre parênteses, indicando a sigla $J C$ junto ao número da série e a página, e correspondem, em ordem cronológica, às seguintes edições: LINs, Álvaro. Jornal de crítica ( $1^{\text {a }}$ série). Rio de Janeiro: José Olympio, 1941; LINs, Álvaro. Jornal de crítica (2a série). Rio de Janeiro: José Olympio, 1943; LINs, Álvaro. Jornal de crítica ( $3^{\text {a }}$ série). Rio de Janeiro: José Olympio, 1944; LINs, Álvaro. Jornal de crítica (4a série): Rio de Janeiro: José Olympio, 1946; LINs, Álvaro. Jornal de crítica ( 5 a série). Rio de Janeiro: José Olympio, 1947; LINs, Álvaro. Jornal de crítica (6a série): Rio de Janeiro: José Olympio, 1951; LINs, Álvaro. Jornal de crítica ( $7^{a}$ série). Rio de Janeiro: O Cruzeiro, 1963.

4 A década de 1940 foi a mais prolífica para a crítica de Álvaro Lins; nos anos de 1950 ele começa a atuar mais diretamente na política e na década de 1960 ele se dedica a reeditar sua obra, mas sem nova produção de grande relevância.
} 
talmente - por serem circunstanciais - de falta de rigor analítico; 5 e, por outro lado, responder - com o exame das reflexões do próprio ensaísta - às acusações de que seu impressionismo e personalismo crítico, reflexos de seu ideal de autonomia para a crítica, afastavam, de forma absoluta, sua crítica jornalística de qualquer elaboração intelectual rigorosa e teoricamente consistente. ${ }^{6}$ Lins endossava a busca de um equilíbrio entre o elemento impressionista e o rigor metodológico para se atingir uma crítica mais consistente sem abrir mão da liberdade e do elemento criador:

Sabemos que a crítica não é só impressionismo, não é só apreciação ou julgamento no plano subjetivo. Não é somente uma arte. Por outro lado, porém, ela não pode fechar-se nos limites de um seco objetivismo, não pode tornar-se prisioneira das leis e dos conceitos das outras ciências. A crítica se forma de uma união mais complexa de elementos objetivos e subjetivos. Existe necessariamente uma ciência da literatura, que exige conhecimentos especializados e metodologia própria. E sobre ela ergue-se a crítica criadora, livre nos seus movimentos de espírito, conquanto apoiada e impulsionada pela ciência

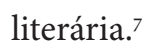

Além dos volumes do Jornal de crítica, receberão aqui especial atenção as famosas anotações pessoais do crítico, realizadas no formato de uma espécie de diário sobre leituras, escritas inicialmente sem intuito editorial, porém publicadas depois em jornais

5 O "veto" acadêmico ao legado intelectual de Álvaro Lins e da chamada "crítica de rodapé", em geral, foi analisado em rocha, J. C. Crítica literária: em busca do tempo perdido? Chapecó: Argos, 2011. O pontapé inicial para esse fenômeno teria sido a polêmica entre Lins e Afrânio Coutinho, pioneiro da crítica acadêmica no Brasil e introdutor das concepções teóricas do New Criticism entre nós. Álvaro Lins e Afrânio Coutinho estiveram no centro de um debate que se tornou emblemático como marco justamente desse momento de radical transformação no paradigma de legitimação do discurso crítico-literário. O episódio demarca, para muitos, o início da moderna crítica literária no Brasil e o início da hegemonia da crítica universitária como "diretora" dos rumos do pensamento crítico no país.

6 Para uma seleção de artigos e ensaios de Álvaro Lins em que o crítico refletiu teoricamente sobre a própria atividade da crítica literária, ver: LINS, Álvaro; MAIA, Eduardo Cesar (org.). Sobre crítica e críticos: ensaios escolhidos sobre literatura e crítica literária, com algumas das Notas de um Diário de crítica. Recife: Cepe Editora, 2012.

7 LINS, Álvaro. Literatura e vida literária: Notas de um Diário de crítica. Diário e confissões. Rio de Janeiro: Civilização Brasileira, 1963, pp. 101-2. 
e compiladas em seguida como Notas de um diário de crítica. ${ }^{8} \mathrm{O}$ tom desses textos é quase sempre confessional; outras vezes, jocoso e polêmico; algumas vezes, ainda, terno e sentimental. Nelas se encontram, permeando observações pessoais sobre obras, escritores e situações da vida literária, algumas argutas teorizações a respeito da literatura, da crítica e de seus papéis na vida individual e social. A análise dessas "notas", portanto, obedece aqui ao mesmo objetivo exposto anteriormente: demonstrar que a crítica literária de Álvaro Lins possui rigor intelectual e, por vezes, estatura teórico-filosófica, na medida em que reflete sobre seus próprios fundamentos e valores.

\section{O CRÍTICO APRESENTA SEU IDEÁRIO}

Cada homem carrega apossibilidade dese tornar umasurpresa capaz de desmoralizar todas as leis sociológicas e psíquicas.

Álvaro Lins, JC1

Em "Itinerário", texto publicado pela primeira vez no Correio da Manhã em 10 de agosto de 1940, e que é a peça de abertura do Jornal de crítica - $1^{a}$ série, Álvaro Lins realiza um procedimento muito comum entre os críticos da época. Ao assumir um rodapé como "crítico titular" de determinado veículo jornalístico, era de praxe que o novo colunista apresentasse, no artigo inaugural, uma espécie de "declaração de intenções" ou "profissão de fé". Com apenas 28 anos, portanto, o jovem intelectual, recém-chegado ao Rio de Janeiro, teve que elaborar e apresentar publicamente, pela primeira vez, uma visão pessoal a respeito da atividade crítica. Tal artigo é, naturalmente, de grande interesse para este estudo.

Como se depreende da leitura de "Itinerário", Álvaro Lins endossou, desde o início de sua carreira, a compreensão da literatura como um fenômeno complexo, inevitavelmente relacionado a questões de ordem tanto estética quanto ética, e em estreito contato com a história, com a política e com as convicções e valores individuais de quem escreve, de quem lê e de quem analisa. Para ele, o crítico deve ter, além da intuição e de

8 A totalidade dessas "notas" foi publicada em lins, Álvaro. Literatura e vida literária: diário e confissões, cit. (Introduções com estudos de Sérgio Milliet, Wilson Martins, Mauro Mota e José César Borba). A edição reúne as Notas de um Diário de crítica, $1^{\circ}$ volume (segunda edição) e $2^{\circ}$ volume (primeira edição). 
um conhecimento abrangente (valor da erudição), a acuidade para estabelecer relações e analogias entre o especificamente literário e os problemas que se encontram na realidade mais ampla, da vida social e individual. ${ }^{9}$ Assim, para ele, uma crítica estritamente imanentista, desvinculada de qualquer aspecto contextual, teria um alcance bastante limitado: "o crítico que se cinge ao círculo do que ele critica está esterilizado pelo seu próprio assunto e não merece este nome" (JC1, p. 11).

Álvaro Lins começa a apresentação de seu ideário mostrando que a crítica de literatura deve estar diretamente conectada ao espírito do seu tempo, mas não pode nunca ser mera reprodução de discursos e valores ideológicos de uma época; a crítica é entendida, portanto, como um verdadeiro trabalho de especulação e reflexão que exige, antes de qualquer coisa, sutileza intelectual e uma postura antidogmática. $\mathrm{O}$ clima político mundial, naquele início dos anos de 1940, era de tensão e apreensão; e as grandes ideologias - nazismo, fascismo e comunismo -, todas de apelo coletivista, apresentavam-se, cada uma a sua maneira, como panaceia para os problemas centrais da civilização. Na contramão desses vieses ideológicos, Álvaro Lins, que já havia se entusiasmado e defendido o integralismo de Plínio Salgado na década anterior, ${ }^{10}$ assume nesse momento uma posição claramente liberal. O jovem crítico apresenta uma defesa radical da individualidade, da personalidade e da liberdade contra as tendências políticas então hegemônicas, principalmente no que tinham fundamentalmente em comum: o espírito coletivista, que tendia a abarcar todas as esferas da vida humana. Para Lins, em sua época, "o que é social parece tudo pretender em direitos sobre o que é individual” (JC1, p. 9).

O crítico assinala que, por outro lado, essa adversidade também faz despontar, como forma de resistência, a autoafirmação individual. E é esse um dos valores fundamentais preconizados em sua crítica literária desde o princípio. Seu ideal é o de tomar "como centro da crítica a personalidade" (JC1, p. 16). Para ele, o individual tem que se sobrepor ao coletivo em arte, principalmente num momento em que predominavam os valores dos "regimes de arte escrava" (JC1, p. 16), como o comunismo e o nazismo.

9 No ensaio "Impressionismo e erudição" (JC2, pp. 284-93), Lins desenvolveu com mais profundidade a concepção de que o ideal da crítica deve ser o de equilíbrio entre esses elementos.

10 Ver o artigo "De integralista a amigo de Cuba". Continente Multicultural. Recife, ano V, n.53, p. 24, maio 2005. Cf. FRANÇA, Humberto; HOLANDA, Lourival. Álvaro Lins: ensaios de crítica literária e cultural. Recife: UFPE, 2007 , p. 27. 
No âmbito artístico, diferentemente das atividades políticas, sociais e econômicas, a realização criativa seria uma operação essencialmente individual - e a crítica deveria sempre levar isso em conta.

Acompanhando o ideal crítico de José Ortega y Gasset, ${ }^{11}$ um dos pensadores que mais influenciaram o intelectual caruaruense, a abstenção da individualidade aparece em Lins como o maior pecado da crítica, seja por escusas ideológicas, formalistas, cientificistas ou por mera preguiça intelectual. Conhecedor e admirador da obra de Friedrich Nietzsche - apesar de ser um católico militante -, o crítico adotou uma forte atitude de prevenção ao que o pensador alemão chamava "espírito de rebanho". Álvaro Lins muito cedo em sua carreira literária se dá conta de que o público em geral e, muitas vezes, mesmo os intelectuais simplesmente repetem e reproduzem opiniões que estão socialmente estabelecidas, sem nenhuma visão pessoal, renunciando à personalidade, ao exame próprio. Caberia ao crítico, pois, ser uma espécie de "diretor de consciências" que orientaria os leitores "para o seu verdadeiro gosto" (JC1, p. 17). A expressão "diretor de consciências" se mostra, por certo, infeliz para o que, de fato, representa o ideal crítico de Álvaro Lins: ela soa como um endosso de uma espécie de caudilhismo intelectual, que fundamentaria o juízo crítico em uma autoridade puramente arbitrária, e não numa capacidade persuasiva legítima, fundamentada na defesa e na condenação de certos valores através de argumentações e sugestões. Um pouco mais adiante, Lins menciona a famosa definição proposta por Sainte-Beuve, um de seus críticos-modelo: "Le critique n'est qu'un homme qui sait lire, et qui apprend à lire aux autres". ${ }^{12}$

O indivíduo seria, portanto, o último refúgio contra todas as formas totalizantes e dogmáticas de compreensão da realidade. Através da defesa da personalidade, o crítico parece querer garantir, como um valor essencial, a independência intelectual e artística em relação aos grandes discursos ideológicos que dividiam o mundo no momento. A arte aparece então como uma espécie de refúgio do indivíduo em meio a esse embate entre sistemas político-ideológicos. A atitude do crítico independente, por conseguinte, é a de defender somente "o partido da literatura", com independência, decisão e

11 Em La rebelión de las masas (1930), obra de caráter mais filosófico e sociológico, Ortega apresenta de forma contundente sua aversão à mentalidade coletivista da época. Cf. ORTEGA Y GASSET, José. A rebelião das massas. Tradução de Marylene Pinto Michael. Revisão da tradução: Maria Estela Heider Cavalheiro. São Paulo: Martins Fontes, 2007.

12 “O crítico não é senão um homem que sabe ler e ensina os outros a ler" (tradução minha). 
coragem, "acima dos grupos, das ideologias, dos partidos, das amizades pessoais, dos regionalismos, de todos os preconceitos" (JC1, p. 15). A posição de Lins, no entanto, não fica tão clara a respeito do que seria propriamente esse "partido da literatura"... A primeira impressão é a de que ele estaria defendendo um tipo de abordagem crítica exclusivamente estética, afastada de fatores e valores contextuais, como os ideológicos e políticos. Contudo, não se trata disso. $\mathrm{O}$ crítico não poderia - ainda que o quisesse emitir seus julgamentos a partir de uma posição neutral, como fica claro pelo que ele afirma algumas páginas depois.

Como julgador, o crítico será sempre ideológico, isto é, debaterá os problemas estéticos e morais em face de suas ideias e do seu gosto, argumentando por adesão ou repulsão. Como interpretador, o crítico será apenas humano, isto é: uma criatura que procura outra criatura, que procura tudo penetrar e tudo entender, num sentido absolutamente humano (JC1, p. 20).

Álvaro Lins estava ciente da relação de interdependência inevitável entre a literatura e as circunstâncias de época e lugar; o que ele não admitia era que o elemento estético, que seria o mais importante na apreciação artística, devesse subordinar-se aos demais; e por isso ele se opunha à ideia de literatura como manifesto ideológico ou como panfleto político, e à postura dogmática em crítica:

$\mathrm{O}$ ato de tudo aceitar, como o ato de tudo negar, não é um ato de crítica. É um ato de positiva ou negativa apologia, e só. $\mathrm{O}$ ato da crítica é aquele que completa, que retifica, que amplia. O que abre perspectivas, o que desdobra situações (JC1, pp. 10-1).

Não parece possível estabelecer disjunções absolutas dentro do pensamento crítico de Álvaro Lins: texto ou contexto, estético ou ético, forma ou conteúdo etc.; ${ }^{13}$ a literatura, como fenômeno vital, supera esse tipo de dicotomia e desafia sempre qualquer pos-

13 Em artigo posterior, o crítico formula de maneira ainda mais clara e direta a sua visão integral de crítica literária e sua aversão a falsas disjunções: "Não sei, na verdade, o que será para a literatura e a arte uma traição maior: se o encerramento numa 'torre de marfim', a indiferença por toda atividade social e política, ou se a paixão partidária, tornando-se exclusivista, a personalidade do artista esgotando-se toda nesta paixão, com o prejuízo da sua obra, com o prejuízo da sua arte” (JC2, p. 266). 
sibilidade de monismo metodológico ou teórico por parte da crítica. A divisa de Paul Souday de que "la critique est à la littérature ce que la littérature est à la vie", repetida pelo crítico pernambucano em mais de uma ocasião, traduz a maneira complexa com que Lins enxergava o fenômeno literário e a atividade crítica.

Outro tema importante que já aparece nesse artigo inaugural diz respeito à compreensão da crítica como um trabalho de criação, próximo, portanto, da própria atividade artística. Para Lins, a crítica é uma "aventura da personalidade" (JC1, p. 14), uma arte, uma forma de criação (e de autocriação) que demanda a construção de um estilo pessoal,${ }^{14} \mathrm{e}$ não somente uma grande capacidade analítica ou uma metodologia rigorosa de investigação literária:

A criação do crítico lhe vem da possibilidade de levantar, ao lado ou além das obras dos outros, ideias novas, direções insuspeitadas, novos elementos literários e estéticos, sugestões de bom gosto, esquematizações, quadro de valores. Crítica num tríplice aspecto: interpretação, sugestão e julgamento (JC1, p. 11).

A crítica personalista e impressionista de Álvaro Lins é atenta às reverberações que a leitura livre e intuitivamente suscita no momento em que é feita, e que somente depois deve ser complementada com métodos e ferramentas de análise, classificação e comparação.

A categorização de Lins como um crítico "diletante", ${ }^{15}$ muito difundida nos meios acadêmicos até os dias de hoje, se deve justamente a que ele não se ateve de forma exclusiva, constante e rigorosa a nenhuma teoria ou metodologia crítica de sua época. Essa é uma questão, porém, que exige maior sutileza. Ele, de fato, acreditava que o maior pecado intelectual seria subordinar a personalidade a leis, regras e métodos inflexíveis,

14 O maior pecado intelectual do crítico, para Álvaro Lins, seria justamente incorrer na impessoalidade, numa linguagem neutra, o que, estilisticamente, se traduziria num "tom indistinto e vago" de escritura (JC1, p. 246), enfim: numa fuga de si mesmo.

15 É curioso que o próprio Álvaro Lins tenha mencionado, em seu primeiro rodapé - antes, portanto, de receber qualquer acusação ou crítica -, a polêmica entre Brunetière, defensor da crítica científica, e Anatole France e Jules Lamaître, representantes da crítica impressionista, que foram acusados pelo primeiro de "diletantismo crítico". Lins ainda sugere que são mais graves os erros de um crítico pretensamente científico (como o próprio Brunetière ou H. A. Taine), preso a um método falacioso, do que um erro pontual de um indivíduo que obedece a sua própria intuição.

Teresa revista de Literatura Brasileira [18]; São Paulo, 2017 • 85 
anulando a criatividade e a possibilidade de surpresas, do surgimento de elementos novos, principalmente no momento do contato com as obras artísticas. Se a "vida do espírito", que seria o alicerce das artes, é marcada pelo imprevisto, pelo imponderável, não há método ou sistema que possa abarcá-la completamente. Não se trata, para Lins, de negar a ciência e suas possíveis contribuições para a crítica literária, mas de aprender, com a experiência, que o entendimento da literatura exige um olhar relativo e compreensivo, nunca dogmático.

Para o crítico, o apogeu e o êxito da ciência teriam feito com que ela tentasse abarcar tudo, mesmo a arte e a literatura. Mas, "como julgar [...] uma obra de arte dentro de determinados métodos, dentro de regras formuladas aprioristicamente - quando ela pode, em qualquer momento, ultrapassá-los ou fugir deles?" (JC1, p. 12).

Um ponto bastante problemático que aparece nas primeiras reflexões críticas de Álvaro Lins se refere à sua posição no debate, candente na época, a respeito da legitimidade intelectual da chamada crítica católica. $\mathrm{O}$ antidogmatismo e a independência do pensamento crítico de Lins - um católico devotado e militante à época - são, nesse sentido, colocados à prova. Submeter a personalidade e a capacidade crítica individual a qualquer forma de compreensão prévia e totalizadora da realidade configuraria, portanto, uma atitude anticrítica. O crítico, por sua vez, tentou conciliar e justificar, de maneira nem sempre convincente, diga-se, o dogmatismo da fé religiosa com o valor, para ele essencial, da independência intelectual. Chegou a afirmar, com um argumento claramente artificioso, a superioridade natural da posição dos críticos católicos:

Nenhum outro como o crítico católico conta com tantos elementos para ser livre, imparcial e justo. [...] Não digo que os outros, os não católicos, estejam privados dessas qualidades, mas o que afirmo é que o catolicismo torna-as mais propícias e mais firmes (JC1, p. 21).

A falácia evidente se encontra justamente na afirmação de que os críticos católicos, por essência, não se submeteriam a paixões e partidarismos, e que teriam uma absoluta capacidade de compreender e julgar os particularismos dos outros desde um ponto de vista imparcial, pois só os moveriam os ideais transcendentais de beleza e pureza. A atitude do católico, para o então jovem crítico, só poderia ser a de piedade e compreensão.

Lins admite que, de fato, "um homem católico em nenhuma ocasião poderá esquecer ou renegar essa 'marca"' (JC1, p. 19), pois ele tem que ser antes de tudo um católico, mas isso, para o crítico, não implicaria uma determinação prévia de todas as suas valorações e de suas opiniões, porque existiria um amplo espaço de liberdade na 
vida mundana no qual a visão geral do catolicismo não interferiria: algo como "a César o que é de César...”. Não fica claro, no entanto, até que ponto essas duas realidades - a da vida mundana e a da vida religiosa - podem ser divorciadas. Quando Lins se referia ao crítico e líder católico Tristão de Athayde, por exemplo, mostrava sempre uma admiração quase epigonal, mas não deixava de reconhecer que o amigo (e mestre) muitas vezes levava longe demais, em sua crítica literária, as próprias crenças morais e convicções religiosas e acabava usando argumentos éticos em momentos em que deveria priorizar os de ordem estética.

Em outra passagem, Lins chega a afirmar, num comentário a respeito do escritor e crítico católico francês François Mauriac, que "uma crítica católica, rigorosamente, não existe" (JC1, p. 18), porque isso seria admitir que existissem uma estética, uma ciência e um sistema político católicos, quando, na verdade, seriam esses independentes.

O fato é que Álvaro Lins nem sempre demarca apropriadamente, em sua própria crítica, essa separação entre o conhecimento religioso da realidade - totalizador e perene - e o âmbito temporal, material e contingente da vida mundana. A contradição interior que Gilberto Freyre acertadamente enxergou no amigo ${ }^{16}$ parece ter origem nesse conflito entre o essencialismo e o universalismo de uma visão religiosa de mundo e a postura inquisitiva, e mesmo cética, que ele admirava em livres-pensadores como Montaigne ou Gide, e que estava, ainda que de forma agônica, ${ }^{17}$ fortemente presente em sua própria crítica. ${ }^{18}$

Abordando o tema da religião em Álvaro Lins, Adélia Bezerra de Meneses Bolle insinua que a condição de católico influenciava negativamente sua crítica, porque, como

16 Como se lê na nota LXv do $1^{\mathrm{o}}$ volume do Diário de crítica de Lins: “A propósito de G. F. [Gilberto Freyre], eu havia escrito: - é um cético com a nostalgia da Igreja e de Deus. Dias depois ele me respondeu: - O seu caso é exatamente o contrário: um católico com a nostalgia do ceticismo. Essa resposta deu-me a esquisita sensação de quem se vê descoberto. Um católico com a nostalgia do ceticismo - esta frase é meu próprio retrato. $\mathrm{O}$ retrato de uma contradição interior que nenhum recurso dialético consegue apaziguar" (LINs, Literatura e vida literária: Notas de um diário de crítica, cit., p. 57).

17 A vivência do cristianismo em Álvaro Lins, apesar de certas posições dogmáticas de juventude, assemelha-se, a meu ver, aos exemplos de Georges Bernanos e Miguel de Unamuno: pensadores não doutrinários, que compreendiam a fé não como um conjunto de regras, mas como agonia, como um debate interno entre a crença institucional e suas próprias tendências e interpretações pessoais.

18 Em alguns artigos posteriores Álvaro Lins voltará ao tema da crítica católica, mas já de forma menos intensa e apaixonada. 
homem de fé, ele se considerava em posse de algumas verdades morais básicas e universais. Bolle diz que sua personalidade era marcada como a de alguém que se achava "proprietário da verdade". 19 Tal ponto de vista pode ser parcialmente rebatido justamente através do argumento de que a crítica de Álvaro Lins era, antes de tudo, caracterizada pelo seu individualismo personalista, pouco afeito à aceitação de verdades estabelecidas. Além disso, o crítico, em diferentes momentos de sua trajetória, demonstrou possuir a sutileza de inteligência que lhe permitia - se não a autoironia - pelo menos a revisão de suas posições e a autocrítica, mesmo em relação a temas de natureza religiosa. Em artigo publicado alguns meses depois de "Itinerário", por exemplo, afirmou:

É que, tanto no domínio do propriamente cultural como no domínio político, os católicos estão sempre chegando tarde demais ou nunca chegando. Em geral não sabemos conhecer a verdade quando ela se acha com os não católicos. Combatemos muitas vezes certas situações oportunas e justas simplesmente porque seus autores não são homens de igreja (JC1, p. 356).

Álvaro Lins tampouco aprovava a obra de arte que colocasse a orientação religiosa antes das preocupações estéticas: "A literatura religiosa não deve ser intencionalmente procurada" (JC2, p. 126). O escritor que assumia a finalidade precípua de apostolado e de propaganda tomava um caminho, para Lins, antiliterário. Com raras exceções, seus

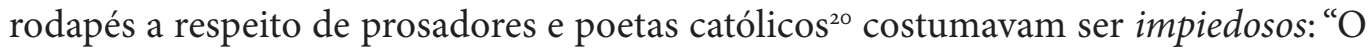
mau gosto artístico, o sentimentalismo piegas, o primarismo intelectual constituem os sinais mais característicos da literatura religiosa no Brasil" (JC2, p. 126).

Outro exemplo de independência intelectual pode ser encontrado na polêmica que travou com o também crítico católico Tristão de Athayde a respeito da situação da ditadura de Franco na Espanha. ${ }^{21}$ Muitos intelectuais católicos do período defendiam a legitimidade do franquismo justamente pelo fato de o regime contar com sustentação

19 Bolle, Adélia Bezerra de Meneses. A obra de Álvaro Lins e sua função histórica, cit., p. 97.

20 Receberam mais avaliações positivas do que negativas, por exemplo, as obras do romancista Octávio de Faria e dos poetas Augusto Frederico Schmidt, Jorge de Lima e Murilo Mendes.

21 Sobre as reflexões e debates de Álvaro Lins com outros pensadores católicos a respeito do franquismo, ver, principalmente, "Agonia de um católico" e "Noite de agonia", capítulos finais da $1^{a}$ série do Jornal de crítica. 
eclesiástica. Lins, desde o princípio, mostrou-se contrário ao nacional-catolicismo de orientação fascista e antiliberal do governo espanhol, porque este não resguardava as liberdades individuais e se baseava principalmente na autoridade da força. No último Jornal de crítica, já na década de 1960, portanto, Lins volta ao tema e se refere com admiração ao fato de que alguns padres presos pelo regime de Franco não aceitaram receber a comunhão nas prisões após descobrirem que os sacerdotes simpáticos ao ditador tinham instituído o procedimento religioso de forma obrigatória nas cadeias. $\mathrm{O}$ crítico se posiciona muito claramente no sentido de que, para ele, a liberdade individual - da vida interior e da consciência, principalmente - deve ser o valor mais importante:

Sim, compreendo e sinto, em toda a sua extensão, este gesto de revolta de homens católicos, que se privam do sacramento da comunhão, que jogam assim, perigosamente, $o$ que consideram a sua eternidade, entre o Céu e o Inferno, para afirmar a sua liberdade interior contra a opressão e a injustiça $(J C 7$, p. 126).

\section{AS PRERROGATIVAS DO INDIVÍDUO FRENTE ÀS IDEOLOGIAS}

A defesa do individualismo e do personalismo crítico em Álvaro Lins está fortemente presente também em suas reflexões sobre a política. A importância atribuída por ele à liberdade e à inviolabilidade da consciência individual frente às concepções totalizadoras de mundo, seja no âmbito da ideologia ou no da prática política efetiva, é fundamental para a compreensão de sua personalidade crítica e mesmo para o entendimento de sua visão de arte e literatura como espaço de autoformação, criação e liberdade.

É preciso entender a posição política de Lins como uma forma de enfrentamento das questões mais prementes do seu tempo, marcado essencialmente pelo embate entre as grandes concepções ideológicas de então. Apesar de não rotular suas convicções, o crítico se coloca na fileira dos intelectuais liberais e apresenta, em momentos diversos, os valores fundamentais de seu pensamento político tomando como base os princípios de proteção ao indivíduo contra os poderes discricionários e a defesa da liberdade como forma de desenvolvimento da personalidade, acima de interesses coletivistas.

Alguns problemas conceituais podem ser encontrados na formulação da "teoria política" do crítico, principalmente quando este tenta conferir valor universal e absoluto à liberdade do indivíduo, sem levar em conta as inevitáveis restrições que ela sofre dentro de qualquer sistema social, como fica claro na consideração de que "Da liberdade do 
homem nenhum mal poderá advir, o que significa que o estado será mais uma entidade abstrata e jurídica do que uma máquina de domínio" (JC1, p. 255, grifo meu). Apesar da fragilidade idealista de tal concepção, as bases liberais do seu pensamento possibilitaram que ele conquistasse uma posição de independência em relação aos sistemas ideológicos dominantes à época, o que impelia seu pensamento a ser mais ágil e sutil no enfrentamento dessas questões - e reforçava ainda mais sua busca por autonomia intelectual.

Sua perspectiva particular sobre a política, que misturava valores católicos com elementos do pensamento liberal, levou-o a colocar, equivocada e redutoramente, filósofos e ideólogos tão diversos como Nietzsche, Marx, Maquiavel, Hitler e Stalin numa mesma trincheira, como "teóricos e executores desses regimes que se movimentam sob o princípio da maldade e da indignidade do homem" (JC1, p. 254). Lins acreditava que todos eles tinham em comum uma visão pessimista da natureza humana individual, o que os levara a formular que "porque o homem é mau e corrompido, não se lhe deve permitir nenhuma liberdade, que por consequência será utilizada para fins igualmente maus e corrompidos" (JC1, p. 254). Apesar de tudo, a sutileza do contraponto católico-liberal de Lins, gradualista e antirrevolucionário, aparece quando ele afirma que "A concepção de uma sociedade baseada na bondade do homem resulta, apenas, num erro que os próprios homens podem corrigir em qualquer momento" (JC1, p. 255); mas a outra forma, baseada na ideia de uma maldade essencial, requer um Estado rígido, supercontrolado, que limita a ação humana reformista. Para ele, o mal evidente do darwinismo social é, apesar de tudo, menos execrável do que a defesa de um estado absorvente e tirânico que rege a vida dos homens. Contrapondo-se aos dois modelos anteriores, Lins defende uma concepção Cristã de vida, "rigorosamente realista", segundo ele (JC1, p. 255), na qual o homem não seria visto nem como anjo, nem como besta: uma concepção que admite o pecado, mas também a salvação.

Portanto, dentro das concepções políticas de Álvaro Lins, o valor mais fundamental é o de que nenhuma forma de poder deve anular a personalidade, a individualidade: "Defendemos para os homens o direito de existência como seres independentes, como indivíduos autônomos, como personalidades livres" (JC3, p. 11).

A postura intelectual de cautela em relação à real capacidade que teorias e sistematizações gerais têm de darem conta, de maneira cabal, da complexidade da realidade humana é uma das marcas do pensamento de Álvaro Lins e se manifesta em relação a temas diversos. No âmbito específico de suas reflexões políticas, essa desconfiança se traduziu numa crítica muito bem articulada ao elemento utópico fortemente presente nos discursos ideológicos - fossem de esquerda ou de direita - da época. Lins muitas 
vezes procurou deixar patente o caráter puramente abstrato, esquemático e idealista dos sistemas quando contrastados com a experiência política real:

Que ninguém se deixe levar, no entanto, pela ilusão de um sistema político transportado fielmente para a realidade, de uma ordem prática conformada, em exatidão, dentro de uma ordem teórica. Será preciso contar sempre com o imprevisto (JC4, p. 205).

Mais uma vez, o único antídoto intelectual possível é o resguardo da liberdade de ação da consciência individual e a não aceitação de fórmulas prontas. Na contramão da paixão ideológica e da tendência ao adesismo total numa ou noutra trincheira política da época, Lins prometia manter sempre o espírito crítico, alerta e livre. E concluía: "Permanecer solitário, acima dos partidarismos fanáticos, não é, em certos momentos, fraqueza ou covardia, mas afirmação de personalidade" (JC4, p. 208).

É possível, assim, traçar uma clara analogia entre o papel que Álvaro Lins atribui ao crítico literário e cultural e a função que ele confere a qualquer intelectual de orientação liberal no âmbito das discussões político-ideológicas:

A tendência do Estado é alargar os seus poderes, tornar-se intervencionista, e o papel dos intelectuais é o de defender a estrutura do indivíduo, estimular-lhe o senso da liberdade e do poderio pessoal, para que se recuse a uma incorporação anuladora. Pelo seu próprio caráter, a função da inteligência é libertadora, dialética, oposicionista e revolucionária $\left(J C_{5}, \mathrm{p} \cdot 37\right)$.

Mesmo após a famosa guinada política pela qual o crítico passou a partir dos anos de 1960 - quando assumiu a militância de esquerda após voltar de sua experiência diplomática em Portugal -, ${ }^{22}$ é possível afirmar que o valor da liberdade individual ainda

22 Na verdade, bem antes ainda da década de 1960, em alguns textos, sente-se que o crítico passa a rever sua oposição ferrenha ao socialismo e ao marxismo, passando a conceder-lhes, se não sua simpatia, pelo menos o reconhecimento da justiça de algumas de suas demandas sociais e também o valor de certas críticas ao modelo capitalista. Já em 21 de maio de 1943, por exemplo, em “Ideias e acontecimentos", Lins afirma que "Estar em desacordo com a concepção da vida dada pelo marxismo não quer dizer, por exemplo, que aceitemos a campanha de difamação que durante vinte anos o capitalismo levantou contra a Rússia" (JC4, p. 207). O crítico diz ainda que "Toda a crítica do marxismo ao capitalismo é de uma admirável lucidez. O erro do marxismo, no entanto, está no seu monismo econômico” (JC4, p. 210). 
permaneceu como o centro de suas convicções políticas: "Eis uma boa fórmula: direção na economia, liberdade nos espíritos" (JC4, p. 214), sintetizou o crítico.

Uma melhor explicação das flutuações e transformações pelas quais passou o pensamento político de Álvaro Lins exigiria um estudo mais detalhado e específico. Aqui, a intenção foi, especificamente, a de mostrar a estreita relação que se vislumbra entre seu individualismo político e sua concepção do papel do intelectual e, particularmente, a do crítico literário. Todos esses posicionamentos e valores de natureza prioritariamente política tiveram, na obra do crítico, uma repercussão muito clara e pragmática em sua atividade crítica e na compreensão que ele tinha sobre a literatura e a arte em geral. A partir das circunstâncias políticas extremamente delicadas do seu tempo, Lins fortaleceu a convicção de que o desenvolvimento de todas as formas de arte depende da garantia da liberdade individual, pois a arte não é, nem poderia ser, como atividade fundamentalmente criativa, submetida a qualquer forma de dirigismo, seja político, ideológico, religioso ou teórico. Assim, para Lins, impedir a livre manifestação da individualidade é esmagar o elemento que possibilita a verdadeira criação artística.

Ainda sobre o tema, cabe uma última ressalva. Não se trata, para o crítico, de se estabelecer uma separação total entre o âmbito da arte e o da política. Na verdade, o que Lins parece preconizar - às vezes de forma clara, às vezes de forma enviesada - é que as duas dimensões, a estética e a político-ideológica, estão relacionadas no mundo de uma maneira indissociável, e se desenvolvem em constante diálogo e confrontação uma com a outra. Contudo, a sutileza da postura crítica de Álvaro Lins consistiu em tentar, na medida do possível, não ideologizar a estética nem, muito menos, estetizar a política. A inteligência crítica e a fidelidade a si mesmo parecem ser, neste quesito, as únicas ferramentas para o crítico prudente e, ainda assim, nunca se terá a garantia de isenção e imparcialidade totais.

Eduardo Cesar Maia é Professor Adjunto da Universidade Federal de Pernambuco 